\title{
Sex differences of human corpus callosum revealed by polar coordinate system: magnetic resonance imaging study
}

\author{
G. Spasojević ${ }^{1}$ S. Malobabić ${ }^{2}$ D. Mikić3 , S. Vujnović ${ }^{3}$, O. Pilipović Spasojević4 , A. Maliković ${ }^{2}$ \\ ${ }^{1}$ Department of Anatomy, Faculty of Medicine, University of Banja Luka, Bosnia and Hercegovina \\ IInstitute of Anatomy "Dr Niko Miljanić", Faculty of Medicine, University of Belgrade, Belgrade, Serbia \\ 3Institute of Clinical Radiology, Clinical Centre of Banja Luka, Republic of Srpska, Bosnia and Hercegovina \\ "Department of Physical Medicine and Rehabilitation "Dr M Zotović", Banja Luka, Republic of Srpska, \\ Bosnia and Hercegovina
}

[Received 11 December 2014; Accepted 23 February 2015]

Background: Evaluation of morphological and size changes related to various pathological conditions of the corpus callosum (CC) requires the data about sex dimorphism of the CC. The purpose of our study is to define potential morphological sex differences of the CC by the use of polar coordinate system as a system of measurements. Materials and methods: After division of the CC into three equal segments by the use of polar coordinate system, we investigated the length of the hemisphere $\left(A-A^{\prime}\right)$, the CC size as its midsagittal section area (CCA), the size of its segments $(C 1, C 2, C 3)$, thickness of the thinnest part of the CC (TCC) and the angular coordinate ( $\alpha$ angle) of dorsal point of the TCC in a sample of 30 human brains magnetic resonance images (15 males and 15 females, age 20-50 years).

Results: We found significantly larger CCA, C3 segment and the TCC in males. Statistically significant correlation in both, males and females, was found between parameters of the $C C A$ and of all of its segments $(C 1, C 2, C 3)$, the $C 1$ and $C 2$, the C2 and C3 segments, as well as like as between the C2 and TCC. Sex differences were also in findings of significant correlation between the C1 and C3 segments, between CCA and TCC, and of significant negative correlation between the $\alpha$ angle and $A-A^{\prime}$ only in females.

Conclusions: We concluded that the use of polar coordinate system appropriately reflects the anatomical and encephalometric characteristics of human CC. (Folia Morphol 2015; 74, 4: 414-420)

Key words: human brain, sex dimorphism, corpus callosum, magnetic resonance imaging, encephalometry

\section{INTRODUCTION}

Corpus callosum (CC), the largest interhemispheric connection of human brain, contains commissural, perforating and decussating fibres $[14,21]$. In addition to exclusively diagnostic and neuropathological purposes, the morphological studies of the CC could obtain additional data about human brain functio- ning and disorders [24]. Before the introduction of magnetic resonance imaging (MRI) autopsy studies of the CC $[9,17,19,20,28]$ as well as all subsequent imaging studies on living persons resulted only in the general conclusion $[4,10]$ that the $C C$ is very variable in its form and size. After the introduction of MRI, increased number of studies did not finally resolved

Address for correspondence: Prof. G. Spasojević, Department of Anatomy, Faculty of Medicine, University of Banja Luka, ul. Danila Perovica 8, 78000 Banja Luka, Bosnia and Hercegovina, e-mail: goraspas@yahoo.com 
the problem of relationships of the CC morphology to sex, handedness and age. Generally, in MRI studies there are obvious lack of standards and vast diversity of methods applied for quantifying the size and for defining the shape of the $\mathrm{CC}$ and its subdivisions. For discussion and overview of conflicting results, as well as for exhaustive reviews of errors and numerous causes of potential false conclusions see several papers $[1,3,10,12,18,28]$. In short, there are three main areas of important methodological problems: 1) sampling and subject material, 2) measurement procedure, and 3) appropriateness of using absolute or relative values [6].

In the studies of the CC size and morphology, including measurements of midsagittal surface area, were used: straight-line method (genu-splenial line, intercommissural line and Chamberalin's line) [6], curved-line method, bent line method (centre of gravity, medium line from the rostrum to splenium) [4], and radial gravity method [3]. These methods included different subdivisions of the $\mathrm{CC}$, like subdivision in 7 subareas using the length of the CC [28] or the intercommissural line [26], division in 4 unequal subareas using intercommissural line [15], and the indexes, like slenderness index [4] or callosal ratio [26].

In addition to the size measurements, the CC shape was studied by spatial normalisation (based on an elastic wrapping of Tailarach atlas) as common reference system for intersubject comparisons [7], by Jacobian determinant maps, showing the shape but not size differences between images (results depending on the template used) [8], or by skeletal shape analysis [24]. The shape of the CC was quantified using elliptic Fourier analysis for a global evaluation of the shape independent of the size, spatial orientation, and relation to reference planes [10].

These methodological controversies influenced the findings about sex differences of the CC. So, a dramatic sex differences in the shape of the $\mathrm{CC}$ were observed, but without conclusive evidence of sexual dimorphism [1]. In most of older women there was a slender and almost symmetrical CC [10]. Females tend to have a smaller CCA, with its larger posterior fraction, the more slender CCs, the more bulbous splenium [4], larger splenium, and different pattern of age related changes [8]. We can add our previous finding of highly significant correlation between the CC area (CCA) and perimeter of the CC only in males [25].

The aim of our study is to define potential morphological sex differences of the CC by the use of polar

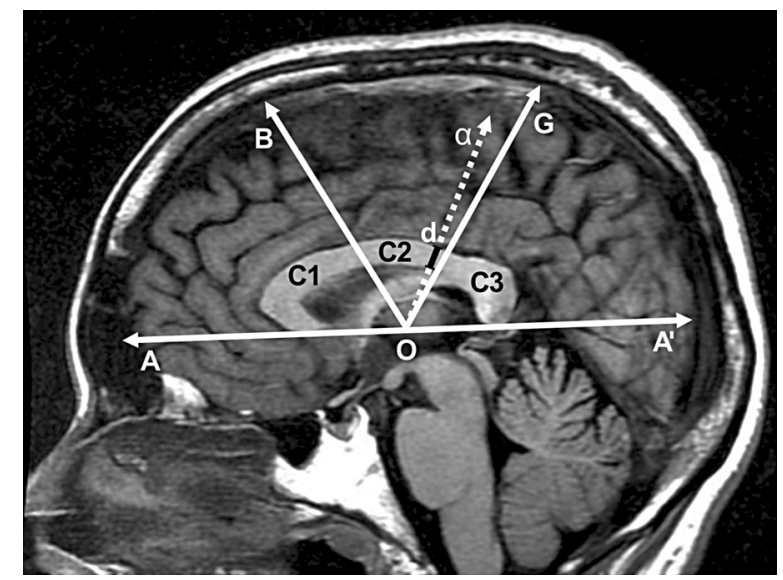

Figure 1. Magnetic resonance imaging brain midsagittal scan with added polar coordinate system; $A-A^{\prime}$ - length of the hemisphere (in $\mathrm{mm}$ ) along polar axis; angular coordinates $B$ and $\mathrm{G}$ at angles of $60^{\circ}$; segments of corpus callosum: $\mathrm{C} 1$ (angle AOB), C2 (angle BOG) and $\mathrm{C} 3$ (angle GOA); $d$ - dorsal point of the thinnest segment of corpus callosum. Angle $\alpha(\mathrm{AOd})$ is angular coordinate of the point $\mathrm{d}$.

coordinate system. In available literature we did not find any of the studies which used this method. We have chosen this approach because it is based on the CC appearance as arching hippocampal formation around the upper part of the circumference of a circle, with temporal lobe curving further round with the developmental hippocampal rotation [11].

\section{MATERIALS AND METHODS}

Investigated sample consisted of 30 healthy subjects, $20-50$ years of age ( 15 females and 15 males; average age of male subjects $35.86 \pm 7.98$ years; of females $34.26 \pm 8.74$ years). Patient images were selected from routine examinations at Institute of Clinical Radiology, Clinical Centre of Banja Luka in accordance with Ethical Principles for Medical Research Involving Human Subjects [29].

Serial MR scans in sagittal, coronal and axial planes were obtained using Signa HDxt 3.0 T, (General Electric Healthcare, USA), T1W flair sequence, $3 \mathrm{~mm}$ thick slices, without applied contrast medium. Software used for image analysis was the AW Server2, (General Electric; USA), Versio AWS-2.0-5.0. Two neuroradiologists in all cases independently selected same midsagittal images as the most precise for this study.

For the study of the CC morphology we specifically defined polar coordinate system [5]. Polar axis was defined as the line passing through two points: the rostral point presented by the inferiormost point of the anterior part of the $\mathrm{CC}$, and the caudal point presented by the inferiormost point of the splenium (Fig. 1). 
Hemispheric tangent $\left(\mathrm{A}-\mathrm{A}^{\prime}\right)$ is the distance along the polar axis between most anterior point of frontal lobe $(A)$ and most posterior point of the occipital lobe $\left(A^{\prime}\right)$. The midpoint of A-A' along polar axis was defined as the pole (centre) of this system (point O) (Fig. 1). This system (total field of $180^{\circ}$ ) we divided the CC by radial coordinates $B$ and $G$ (at angles of $60^{\circ}$ and $120^{\circ}$ ) into three-equal segments $(\mathrm{C} 1, \mathrm{C2}, \mathrm{C} 3)$ : $\mathrm{C} 1$ - angle $\mathrm{AOB}=60^{\circ}, \mathrm{C2}$ - angle $\mathrm{BOG}=60^{\circ}$ and $\mathrm{C} 3$ - angle GOA' $=60^{\circ}$ (Fig. 1). Following steps were the measurements of: the lengths of the hemisphere (in $\mathrm{mm}$ ), the total surface of the midsagittal $\mathrm{CC}$ section area (CCA in $\mathrm{mm}^{2}$ ), its segments $\mathrm{C} 1, \mathrm{C2}, \mathrm{C3}$ and the thickness of the thinnest part of the CC (in mm). Finally, the position of the dorsal point (d) of the thinnest part of the CC (TCC) was defined as angular coordinate ( $\alpha$ angle - AOd) in relation to polar axis.

\section{Statistical analysis}

Standard statistics included arithmetic means with maximal and minimal values, and standard deviations. Distribution of parameters was tested by Kolmogorov-Smirnov test for equality of variances. Significance of differences in obtained values in relation to age and to sex was tested by Student $\mathrm{t}$-test for small samples $(p<5 \%)$.

\section{RESULTS}

Distribution of all parameters was found to be a normal distribution $(p=0.342)$ and there were not statistically significant differences in age between se$x$ es by Student $t$-test $(p=0.605)$. Obtained values for 15 males $(M)$ and 15 females $(F)$ are shown in Table 1.

\section{Variability analysis of measured parameters in relation to gender}

Significance of differences in relation to gender was tested using Student t-test for small samples $(p<0.05)$. Results of measurements and of statistics (t values) are shown in Table 2 . In Table 2 statistically significant differences $(p>0.05)$ between males and females (indicated by asterisks) were found for the CCA, C3 and for the TCC, being larger in males. All these parameters were significantly larger in males comparing with females (Table 2).

\section{Analysis of Pearson's coefficient of linear correlation}

Significant correlation, both in males and in females, was found between parameters CCA and $\mathrm{C} 1$, $\mathrm{CC}$ and $\mathrm{C2}, \mathrm{CCA}$ and $\mathrm{C} 3$, as well as between $\mathrm{C} 1$ and
$\mathrm{C} 2, \mathrm{C} 2$ and C3 segments. Also, both in females and males, significant correlation between $\mathrm{C} 2$ and TCC was found. Sex differences were in findings of only in males positive significant correlation between the TCC and $\alpha$ angle, and of only in females significant correlations between the CCA and TCC, between $\mathrm{C} 1$ and $\mathrm{C} 3$, and of significant negative correlation between $\alpha$ angle and A-A' (length of hemisphere). Pearson's coefficients of linear correlation in males and females are presented in Tables 3 and 4.

\section{DISCUSSION}

In the available literature we did not find any study of the CC morphology using polar coordinate system. The use of the centre of gravity [4], very similar to our method, showed larger posterior fraction of the CC, more slender CCs and more bulbous splenium in females. This seems opposite to our finding of a larger C3 segment in males, but exact definition of the splenium [12] is probably most complex problem in studies of the CC morphology. Age range in our sample, without old subjects, excluded possibility of significant age effect [12], where most of the older women had a slender and almost symmetrical CC [10], with the tendency of the splenium to expand with age [8]. The genu-splenial line, which we used as polar axis, represents the middle position between two extremes (intercommissural and Chamberalin's lines) of three orientation systems and in fact may prove to contain the fewest number of confounding variables [6].

In studies of the CC sex dimorphism it is not always clear if the general concept of sex dimorphism includes only size differences, only shape differences or both of them. Also, the question of the size can be related to general differences in body and brain size [15]. Forebrain volume approximately $10 \%$ larger in men as compared with women had significant correlation with CCA [26], which corresponds to our finding of significantly larger CCA, C3, and of TCC in males (Table 2). Our finding of significant correlations between the CCA and its segments $(C 1, C 2, C 3)$ in both sexes suggests to adequate subdivision of the CC in polar coordinate system we used. Our previous finding of insignificantly larger CCA in females on autopsy material [25] can be related to better discrimination of tissues on dissection, and to the different involvement of the medial longitudinal striae, more variable than the lateral ones, with individual features which make the supracallosal pattern variable [22]. 
Table 1. Sample and results of all measured parameters

\begin{tabular}{|c|c|c|c|c|c|c|c|c|c|}
\hline $\mathbf{N}$ & Sex & Age & $A-A^{\prime}[\mathrm{mm}]$ & $\mathrm{CCA}\left[\mathrm{mm}^{2}\right]$ & C1 [mm²] & $\mathrm{C} 2\left[\mathrm{~mm}^{2}\right]$ & C3 $\left[\mathrm{mm}^{2}\right]$ & TCC [mm] & $\alpha$ angle \\
\hline 1 & M & 33 & 152.6 & 673.8 & 343.5 & 127.5 & 202.8 & 4.9 & 116.8 \\
\hline 2 & M & 39 & 165.7 & 778.2 & 410.2 & 170.6 & 197.4 & 5.3 & 118.6 \\
\hline 3 & $M$ & 42 & 152.1 & 468.0 & 232.2 & 91.2 & 144.6 & 4.7 & 118.1 \\
\hline 4 & M & 22 & 162.7 & 608.7 & 294.2 & 112.9 & 201.6 & 4.2 & 112.2 \\
\hline 5 & $M$ & 28 & 160.8 & 651.7 & 299.6 & 119.4 & 232.7 & 4.7 & 129.2 \\
\hline 6 & $M$ & 20 & 149.0 & 706.3 & 314.4 & 159.8 & 232.1 & 5.5 & 117.9 \\
\hline 7 & M & 40 & 149.1 & 737.6 & 331.3 & 154.0 & 252.3 & 4.7 & 107 \\
\hline 8 & $M$ & 47 & 153.8 & 694.8 & 296.4 & 150.1 & 248.3 & 5.1 & 124.8 \\
\hline 9 & M & 42 & 162.3 & 669.9 & 358.7 & 92.2 & 219.0 & 2.9 & 107 \\
\hline 10 & M & 30 & 151.2 & 540.9 & 251.9 & 101.2 & 187.8 & 3.3 & 110.5 \\
\hline 11 & M & 40 & 153.5 & 629.8 & 289.9 & 133.3 & 206.6 & 4.6 & 96.3 \\
\hline 12 & $M$ & 32 & 164.7 & 772.5 & 343.5 & 161.2 & 267.8 & 3.9 & 102.8 \\
\hline 13 & M & 40 & 147.7 & 697.3 & 363.2 & 128.8 & 205.3 & 4.0 & 114.2 \\
\hline 14 & $M$ & 40 & 169.1 & 631.5 & 298.3 & 119.9 & 213.3 & 3.5 & 97.8 \\
\hline 15 & M & 43 & 166.9 & 714.7 & 362.2 & 125.8 & 226.7 & 4.3 & 106.1 \\
\hline 16 & $\mathrm{~F}$ & 44 & 142.1 & 619.7 & 311.8 & 108.7 & 199.2 & 3.5 & 134.2 \\
\hline 17 & $\mathrm{~F}$ & 33 & 147.5 & 475.1 & 210.6 & 80.3 & 184.2 & 3.1 & 109.7 \\
\hline 18 & $\mathrm{~F}$ & 42 & 154.1 & 790.3 & 408.9 & 153.2 & 228.2 & 4.6 & 117.4 \\
\hline 19 & $\mathrm{~F}$ & 28 & 153.9 & 558.5 & 250.6 & 111.8 & 196.1 & 2.8 & 91.8 \\
\hline 20 & $\mathrm{~F}$ & 26 & 165.7 & 720.9 & 355.6 & 126.2 & 239.1 & 3.7 & 107.0 \\
\hline 21 & $\mathrm{~F}$ & 27 & 136.4 & 548.7 & 225.1 & 113.6 & 210.0 & 3.9 & 119.0 \\
\hline 22 & $\mathrm{~F}$ & 50 & 149.4 & 621.9 & 302.3 & 117.6 & 202.0 & 3.7 & 107.4 \\
\hline 23 & $\mathrm{~F}$ & 29 & 153.7 & 521.4 & 271.9 & 90.3 & 159.2 & 2.2 & 113.0 \\
\hline 24 & $F$ & 25 & 150.3 & 609.2 & 274.5 & 142.1 & 192.6 & 3.7 & 110.2 \\
\hline 25 & $\mathrm{~F}$ & 27 & 154.1 & 504.9 & 245.6 & 88.9 & 170.4 & 3.8 & 117.2 \\
\hline 26 & $\mathrm{~F}$ & 35 & 159.9 & 619.3 & 299.8 & 128.4 & 191.1 & 3.9 & 109.0 \\
\hline 27 & $\mathrm{~F}$ & 51 & 159.7 & 590.0 & 311.6 & 98.8 & 179.6 & 2.8 & 99.1 \\
\hline 28 & $\mathrm{~F}$ & 38 & 151.3 & 670.9 & 312.9 & 151.9 & 206.1 & 5.2 & 113.0 \\
\hline 29 & $\mathrm{~F}$ & 30 & 145.3 & 591.3 & 271.1 & 130.4 & 189.8 & 4.0 & 112.2 \\
\hline 30 & $\mathrm{~F}$ & 29 & 160.8 & 531.2 & 248.3 & 116.3 & 166.6 & 4.1 & 109.8 \\
\hline
\end{tabular}

A-A' - length of hemisphere along the polar coordinate (in mm); CCA - surface area of total midsagittal section of the corpus callosum and of its segments (C1 — anterior segment, $\mathrm{C} 2$ - middle, $\mathrm{C} 3$ - posterior segment); TCC — thickness of the thinnest part of the CC; $\alpha$ angle - angular coordinate of the dorsal point (d) of thinnest part of the CC in polar coordinate system; $\mathrm{M}$ - males; $\mathrm{F}$ - females

Table 2. Measured parameters in males and females. Statistically significant differences between males and females are indicated by asterisks

\begin{tabular}{|c|c|c|c|c|c|c|c|}
\hline \multirow[t]{2}{*}{ Parameter } & \multicolumn{2}{|c|}{ Mean \pm standard deviation } & \multicolumn{2}{|c|}{ Maximal } & \multicolumn{2}{|c|}{ Minimal } & \multirow[t]{2}{*}{$\mathbf{t}$} \\
\hline & Males & Females & Males & Females & Males & Females & \\
\hline $\mathrm{A}-\mathrm{A}^{\prime}[\mathrm{mm}]$ & $157.41 \pm 7.388$ & $152.28 \pm 7.64$ & 169.10 & 165.7 & 147.7 & 136.4 & 0.0 \\
\hline $\mathrm{CCA}\left[\mathrm{mm}^{2}\right]^{*}$ & $665.046 \pm 82.70$ & $598.22 \pm 83.33$ & 778.2 & 790.30 & 468 & 475.1 & 0.0 \\
\hline $\mathrm{C} 1\left[\mathrm{~mm}^{2}\right]$ & $319.3 \pm 46.21$ & $286.706 \pm 51.20$ & 410.2 & 408.9 & 232.2 & 210.6 & $0.036^{*}$ \\
\hline $\mathrm{C} 2\left[\mathrm{~mm}^{2}\right]$ & $129.86 \pm 25.066$ & $117.23 \pm 22.10$ & 170.6 & 153.2 & 91.2 & 80.3 & 0.1 \\
\hline C3 $\left[\mathrm{mm}^{2}\right]^{*}$ & $215.88 \pm 29.92$ & $194.28 \pm 21.63$ & 267.8 & 239.1 & 144.6 & 159.2 & $0.031 *$ \\
\hline $\operatorname{TCC}[\mathrm{mm}]^{*}$ & $4.337 \pm 0.746$ & $3.667 \pm 0.739$ & 5.5 & 5.2 & 2.9 & 2.2 & $0.015^{*}$ \\
\hline$\alpha$ angle & $111.95 \pm 9.34$ & $111.33 \pm 9.39$ & 129.2 & 134.2 & 96.3 & 91.8 & 0.8 \\
\hline
\end{tabular}

Abbreviations as in Table 1 
Table 3. Pearson's coefficients of linear correlation in males. Statistically significant correlations are indicated by asterisks

\begin{tabular}{lcccccccc}
\hline & Age & A-A & CCA & C1 & C2 & C3 & TCC & $\alpha$ angle \\
\hline Age & 1 & 0.078 & 0.057 & 0.170 & -0.064 & -0.051 & -0.130 & -0.200 \\
A-A & 0.078 & 1 & 0.237 & 0.327 & -0.012 & 0.159 & -0.303 & -0.269 \\
CCA & 0.057 & 0.237 & 1 & $0.855^{*}$ & $0.813^{*}$ & $0.762^{*}$ & 0.258 & -0.038 \\
C1 & 0.170 & 0.327 & $0.855^{*}$ & 1 & $0.519^{*}$ & 0.385 & 0.089 & -0.042 \\
C2 & -0.064 & -0.012 & $0.813^{*}$ & $0.519^{*}$ & 1 & $0.609^{*}$ & $0.616^{*}$ & 0.063 \\
C3 & -0.051 & 0.159 & $0.762^{*}$ & 0.385 & $0.609^{*}$ & 1 & 0.060 & -0.092 \\
TCC & -0.130 & -0.303 & 0.258 & 0.089 & $0.616^{*}$ & 0.060 & 1 & $0.536^{*}$ \\
$\alpha$ angle & -0.200 & -0.269 & -0.038 & -0.042 & 0.063 & -0.092 & 0.536 & 1 \\
\hline
\end{tabular}

Abbreviations as in Table 1

Table 4. Pearson's coefficients of linear correlation in females. Statistically significant correlations are indicated by asterisks

\begin{tabular}{lcccccccc}
\hline & Age & A-A & CCA & C1 & C2 & C3 & TCC & $\alpha$ angle \\
\hline Age & 1 & -0.023 & 0.326 & 0.465 & 0.048 & 0.107 & 0.049 & 0.066 \\
A-A' & -0.023 & 1 & 0.250 & 0.383 & 0.073 & -0.020 & -0.068 & $-0.525^{*}$ \\
CCA & 0.326 & 0.250 & 1 & $0.941^{*}$ & $0.800^{*}$ & $0.808^{*}$ & $0.540^{*}$ & 0.110 \\
C1 & 0.465 & 0.383 & $0.941^{*}$ & 1 & $0.614^{*}$ & $0.630^{*}$ & 0.355 & 0.121 \\
C2 & 0.048 & 0.073 & $0.800^{*}$ & $0.614^{*}$ & 1 & $0.609^{*}$ & $0.753^{*}$ & 0.052 \\
C3 & 0.107 & -0.020 & $0.808^{*}$ & $0.630^{*}$ & $0.609^{*}$ & 1 & 0.470 & 0.086 \\
TCC & 0.049 & -0.068 & $0.540^{*}$ & 0.355 & $0.753^{*}$ & 0.470 & 1 & 0.326 \\
$\alpha$ angle & 0.066 & $-0.525^{*}$ & 0.110 & 0.121 & 0.052 & 0.086 & 0.326 & 1 \\
\hline
\end{tabular}

Abbreviations as in Table 1

However, the average CCA was significantly larger in females after controlling for brain size and age, especially in the young adults [2], as well as the adjusted size of the CC for forebrain volume, without effect of handedness [26].

The question of shape without defined quantitative parameters is difficult to completely resolve because of potential presence of the combination of size and shape differences. The shape eludes morphometrists, because they often apply inadequate methods. Conventional metric approach allows only for the assessment of local modifications and does not take the whole structure of the organs into account [10]. Our findings of negative correlation between alpha angle and the length of hemisphere (A- $\left.A^{\prime}\right)$ only in females, as well as of significant positive correlation between $\mathrm{C} 1$ and C3, and between the CCA and TCC also only in females, correspond to observed greater slenderness and a smaller ideal CC thickness in females [4]. Significant correlation between C2 and TCC we found only in males can be related to our previous finding of highly significant correlation between
CC perimeter and CCA only in males, suggesting to a greater irregularity of the CC contour in males, what is a kind of sex dimorphism [25].

The often investigated region called the isthmus of the CC, larger in male right-handers [28], unfortunately was not identically defined in all studies. In subdivision of the CC identical as by Witelson [28], but using the line parallel to intercommissural line, subdivision A6 named isthmus segment, was proportionally larger in women [7, 26]. However, in division of the CC in 4 unequal subareas using same line, third one was called isthmus [15]. Only the female isthmus was the exception, being not different in size, while in all cases using 3 different methods mentioned above differences between the CC subareas were significant [6]. The CC subdivisions, including isthmus are arbitrary, while any partitioning method should be based on an anatomical rationale. Anatomy, including the development, directions and structure of callosal fibres, vascular bed and glia, must be fundamental in considering functional significance of the CC. Using the method of Witelson [28], among 5 different 
vertical partitions of the CC distinguished by diffusion tensor tractography [27], the lowest anisotropy was found in regions III (fibres to the primary motor cortex) and IV (the posterior one-third minus posterior one-fourth of the CC) [13]. These regions are related to the isthmus or to the TCC in our study. In subdivision of the CC into 3 segments, higher anisotropy in males than in females was in posterior third than in the genu region, reflecting not only differences in the CC size, but also in its macro- and microstructure and in water diffusion [27].

Interesting are our findings of significantly larger TCC in males, and of significant correlation between the CCA and TCC only in females. By autopsy studies the TCC was determined as $4.49 \mathrm{~mm}(2.5-7 \mathrm{~mm})$ [17], or $0.46 \mathrm{~cm}$ [19], what can be more precise from our current MRI findings (males $4.33 \mathrm{~mm}$; females $3.66 \mathrm{~mm}$ ), because of better anatomical resolution of the CC boundaries than MRI. We recommend the use of the TCC [17] as a simply and clearly defined [19] parameter which best represents the total size of the $\mathrm{CC}$ and should be considered as a more precise parameter than insufficiently defined isthmus. It is in relatively constant position in different individuals and databases, in region anterior of the splenium (see Fig. 6 in [12]). Variable fornix attachments to the CC (if present) located mainly $(77 \%)$ in the third quarter of callosal length and in $19 \%$ in its fourth quarter [17], as like as involvement and size of the longitudinal striae and pericallosal vessels $[12,20]$ can bias the results in applied methodology. Therefore the templates, as used in Jacobian determinant maps showing the shape differences, with variations of results depending on the template used $[7,8]$, are not accurate because they do not consider individual anatomy of the CC.

Our method, using polar coordinate system, better corresponds to the anatomy of the $\mathrm{CC}$, which backwards growth reflects the sequence of the $\mathrm{CC}$ development [16] is related to the caudal growth of the cerebral hemispheres [23]. It is also coincident with temporal lobe curving further round with the hippocampal rotation [11]. Combined with our previous studies of the CC, our results point to the use of proposed parameters and the necessity of careful consideration of obtained results in relation to individual anatomy of the CC.

\section{CONCLUSIONS}

We concluded that the use of polar coordinate system appropriately reflects the anatomical and encephalometric characteristics of human CC.

\section{ACKNOWLEDGMENTS}

This study was supported by grant No. 175030 of Ministry of Education, Science and Technological Development, Republic of Serbia.

\section{REFERENCES}

1. Allen LS, Richey MF, Chai YM, Gorski RA (1991) Sex differences in the corpus callosum of the living human being. J Neurosci, 11: 933-942.

2. Ardekani AB, Figarsky K, Sidtis JJ (2013) Sexual dimorphism in the human corpus callosum: An MRI study using the OASIS brain database. Cerebral Cortex, 23: 2514-2520.

3. Bishop KM, Wahlsten D (1997) Sex differences in the human corpus callosum: myth or reality? Neurosci Biobehav Rev, 21: 581-601.

4. Clarke S, Kraftsik R, Van der Loos H, Innocenti GM (1989) Forms and measures of adult and developing human corpus callosum: is there sexual dimorphism? J Comp Neurol, 280: 213-230.

5. Connaly E, Hughes-Hallet D, Gleason AM (2010) Functions modelling change: a preparation for calculus. $4^{\text {th }}$ Ed. Wiley, New York, pp. 494-497.

6. Constant D, Ruther H (1996) Sexual dimorphism in the human corpus callosum? A comparison of methodologies. Brain Res, 7727: 99-196.

7. Davatzikos C, Vaillant M, Resnick SM, Prince JL, Letovsky S, Bryan RN (1996) A computerized approach for morphological analysis of the corpus callosum. J Comput Assist Tomogr, 20: 88-97.

8. Dubb A, Gur R, Avants B, Gee J (2003) Characterization of sexual dimorphism in the human corpus callosum. Neuroimage, 20: 512-519.

9. De Lacoste-Utamsing C, Holloway RL (1982) Sexual dimorphism in the human corpus callosum. Science, 216: 1431-1432.

10. Ferrario VF, Sforza C, Serrao G, Frattini T, Del Favero $C$ (1994) Shape of the Human Corpus Callosum. Elliptic Fourier Analysis on Midsagittal Magnetic Resonance Scans. Invest Radiol, 29:677-81.

11. Hewitt W (1962) The development of the human corpus callosum. J Anat (Lond), 96: 355-358.

12. Herron $\mathrm{TJ}_{L}$ Kang $X$, Woods DL (2012) Automated measurement of the human corpus callosum using MRI. Frontiers Neuroinformatics, 6: 1-15.

13. Hofer S, Frahm J (2006) Topography of the human corpus callosum revisited-comprehensive fiber tractography using diffusion tensor magnetic resonance imaging. Neuroimage, 32: 989-994.

14. Jang Sung H, Kwon Hyeok G (2013) Neural connectivity of the posterior body of the fornix in the human brain: diffusion tensor imaging study. Neurosc Lett, 549: 116-119.

15. Jancke L, Staiger JF, Schlaug G, Huang Y, Steinmetz H (1997) The relationship between corpus callosum size and forebrain volume. Cerebral Cortex, 7: 48-56.

16. Kier EL, Truwit CL (1997) The lamina rostralis: modification of concepts concerning the anatomy, embryology, and MR appearance of the rostrum of the corpus callosum. AJNR, 18: 715-722. 
17. Lang J, Ederer M (1980) Ueber Form und Groesse des Corpus Callosum und das Septum pellucidum. Gegenbaurs Morphol Jahrb, 126: 949-958.

18. Luders E, Toga AW, Thompson PM (2014) Why size matters: Differences in brain volume account for apparent sex differences in callosal anatomy. The sexual dimorphism of the corpus callosum. Neuroimage, 84: 820-824.

19. Malobabić S, Simić S, Marinković S (1985) Significance of the encephalometric parameters of human CC and medial hemispheric surface. Anat Anz, 159: 231-239.

20. Malobabić S, Bogdanović D, Teofilovski G (1987) Morphology of the Human Corpus Callosum: The shape of its mediosagittal section. Gegenbaurs Morphol Jahrb, 133: 403-410.

21. Malobabić S, Prostran M (1992) Morphology suggests the existence of different functional systems in human corpus callosum. lugosl Physiol Pharmacol Acta, 28 (suppl. 9): 105-110.

22. Pavlović S, Stefanović N, Malobabić S, Babić Z, Kostić A, Pavlović M (2009) Longitudinal striae of the human fornix: shape, relations and variations. Surg Radiol Anat, 31: 501-506.

23. Rakic P, Yakovlev PI (1968) Development of the Corpus callosum and cavum septi in man. J Comp Neurol, 132: 45-72.

24. Sampaio A, Bouix S, Sousa N, Vasconcelo C, Fernandez M, Shenton M.E, Goncalves FO (2012) Morphometry of cor- pus callosum in Williams syndrome: shape as an index of neural development. Brain Struct Funct, 218: 711-720.

25. Spasojevic G, Stojanović Z, Šuščević D, Malobabić S (2006) Sexual dimorphism of the human corpus callosum--digital morphometric study. In Serbian. Vojnosanit Pregl, 63: 933-938.

26. Steinmetz $H$, Staiger JF, Schlaug G, Huang $Y$, Jancke $L$ (1995) Corpus callosum and brain volume in women and men. Neuroreport, 6: 1002-1004.

27. Westerhausen R, Kreuder F, Dos Santos Sequeira $S$, Walter C, Woerner W, Wittling RA, Schweiger E, Wittling W (2004) Effects of handedness and gender on macro- and microstructure of the corpus callosum and its subregions: a combined high-resolution and diffusion-tensor MRI study. Brain Res Cogn Brain Res, 21: 418-426.

28. Witelson SF (1989) Hand and sex differences in the isthmus and genu of the human corpus callosum. A postmortem study. Brain, 112: 799-835.

29. World Medical Association Declaration Of Helsinki: Ethical Principles for Medical Research Involving Human Subjects, 64th WMA General Assembly, Fortaleza, Brazil, October 2013 Available at :http://www.wma.net/ en/30publications/10policies/b3/index.html. Accessed August 25, 2014. 